\title{
IMPACTOS DA AUTOMEDICAÇÃO EM TEMPOS DE PANDEMIA COVID-19
}

Jéssica Pacheco da Silva

Larissa de Oliveira de Batista

DOI: http://dx.doi.org/10.18616/intcov27

O uso racional de medicamentos caracteriza-se no uso correto, dose adequada, tempo de uso para cada paciente, levando em consideração a patologia associada. Sem que haja prejuízo para o próprio paciente e para a população.

Nesse sentido, o uso de medicamentos para outras patologias com comprovação clínica, utilizados de forma inequívoca por pacientes que apresentam sintomas do Sars-CoV-2, poderá trazer altos riscos à saúde da população. Além de fazer com que os medicamentos possam faltar para os pacientes que utilizam para doença crônica, baseada em protocolos clínicos e diretrizes terapêuticas. Esse fato demonstra que a indicação da terapia precisa do acompanhamento de profissional médico para diagnóstico de doença e do profissional farmacêutico para orientar sobre problemas relacionados ao medicamento.

As informações que o Ministério da Saúde propõe como medida de prevenção refere-se à medicina baseada em evidências. Porém, até o momento, não existe medicamento ou vacina que venha a erradicar o vírus. Atitudes rotineiras, como lavar as mãos, cuidar da higiene das embalagens, que até o momento passavam despercebidas, estão sendo uma das soluções mais eficazes para evitar o contágio do coronavírus. Esse simples ato torna-se essencial no enfrentamento contra o vírus, além, é claro, do isolamento social e do uso de máscaras.

A crise atual da pandemia causada pela covid-19, que o mundo vem enfrentando nos últimos meses, faz a população entrar em estado emocional grave. Diante do cenário que estamos presenciando, e as devidas providências necessárias, afastamo-nos totalmente do cotidiano vivenciado até então. Com 
essa adaptação, frente à calamidade, os quadros de depressão e Síndrome do pânico estão surgindo cada vez mais, aumentando o uso de medicamentos.

Diante do exposto, o consumo demasiado com medicamentos utilizados de maneira errônea pela população aumentou exageradamente. Assim, o uso irracional de medicamentos tomou frente, por conta dos supostos tratamentos para a covid-19.

Até o momento não existem comprovações científicas sólida dos medicamentos que vêm sendo utilizados para o coronavírus. As medidas de prevenção continuam, e o isolamento, funciona como barreira no combate ao vírus.

\section{OBRAS CONSULTADAS}

BRASIL. Ministério da Saúde. Uso racional de medicamentos. 2007. Disponível em: https://bit.ly/2K8rZy7. Acesso em: 15 maio 2020. 